\title{
A dos y a cuatro patas: el Occidente de Mesoamérica y la relación entre el perro, el humano y viceversa. Una aproximación a través de estudios de caso
}

\section{On two legs and all four: the Western Mesoamerica and the relationship between the dog, the human and viceversa. An approach through case studies.}

\author{
AITOR BRITO-MAYOR \\ Centro de Estudios Arqueológicos, El Colegio de Michoacán. \\ email: aibrimay@gmail.com
}

(Received 1 June 2018; Revised 24 July 2018; Accepted 2 November 2018)

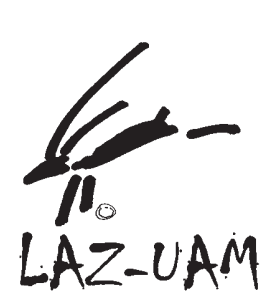

RESUMEN: El Canis familiaris resulta un campo paradigmático de estudio, que ha arrojado considerables resultados dentro de la investigación arqueológica mexicana. Sin embargo, al revisar este fenómeno en la región del Occidente de Mesoamérica, surge la necesidad de realizar una aproximación integradora que no limite su alcance al aspecto psicopompo que cumple este animal. Desde el marco teórico que nos ofrece la Zooarqueología Social, desarrollamos una estrategia de investigación con base en estudios de caso, adscritos a tres subáreas distintas. El sitio de La Mina en las Tierras Altas Orientales es una plataforma habitacional de finales del Epiclásico (AD 500/600-900), con entierros en su base donde aparecen cachorros junto a humanos. Los Guachimontones en el centro de las Tierras Altas Occidentales, urbe neurálgica entre el Formativo tardío y Clásico temprano (BC 100-AD 250), en la que se documentan cánidos domésticos en diversos contextos hasta el Postclásico (AD 900-1521). Por último, en las Planicies Costeras estudiamos el sitio de la Loma Funeraria en la TGNLM y el área residencial y fúnebre de Chocohuistle en el PMTII. La metodología sienta sus bases en acercamientos transdisciplinares, que nos han permitido la reconstrucción biotípica de los cánidos, la estimación de sus tendencias paleodietéticas por XRF y la ubicación temporal de los contextos por AMS. De esta forma accedemos al análisis de la relación entre el perro, el humano y viceversa en sus propios términos, con el objetivo principal de reconocer el contexto social en el que se dio esta simbiosis.

PALABRAS CLAVE: ZOOARQUEOLOGÍA, ARQUEOMETRÍA, PERRO (Canis familiaris), OCCIDENTE DE MESOAMÉRICA

ABSTRACT: The Canis familiaris becomes a paradigmatic field of study, and it has yielded significant results in Mexican research. However, when discussing this phenomenon in the region of the West of Mesoamerica, the need to make an integrative approach arises beyond etnohistoric data. With the theoretical perspective that the Social Zooarchaeology offers, we develop an investigative strategy based on the case studies that are assigned to three different sub-areas. La Mina is in the Eastern Highlands, a housing platform at the end of the Epiclassic (AD 500/600900.), with burials at its base where puppies appear next to humans. Los Guachimontones is in the center of the Western Highlands, a neuralgic city between Late Formative and Early Classic (BC 100-AD 250) in which domestic canids are documented in various contexts until the Postclassic (AD 900-1521). Lastly, in the Coastal Plains, we studied a funerary hill in TGNLM and the residential-funeral area of Chocohuistle in PMTII. The methodological bases used have a hermeneutical orientation, in which the inductive data and the collaboration between transdisci- 
plinary fields prevail. We use analysis of bone remains in primary and secondary levels, estimation of paleodiethetic tendencies by XRF and AMS dating. In this way we access the analysis of the relationship between the dog, the human and viceversa in their own terms, with the main objective of recognizing the social context in which this symbiosis occurred.

KEYWORDS: ZOOARCHEOLOGY, ARCHEOMETRY, DOG (Canis familiaris), WESTERN MESOAMERICA

\section{INTRODUCCIÓN}

La capacidad que tenemos de crear nuestro propio mundo con base en lo que nos rodea hace partícipes a los animales, quedando los domésticos en un plano privilegiado. Es aquí donde la relación simbiótica que hemos entablado con el perro $(\mathrm{Ca}$ nis familiaris) se entiende como objeto de estudio, contribuyendo así a un análisis holístico sobre los grupos humanos del pasado. Relevantes aportaciones dan buena cuenta de ello para la investigación de este fenómeno en Mesoamérica, con especial interés en el Altiplano central y el Sureste mexicano (Valadez Azúa \& Blanco, 2005; Ramos Novelo, 2009; Götz, 2014; entre otros). Por su parte, en la poco trabajada región del Occidente existen evidencias de este vínculo desde el Formativo medio (900 al 300 B.C.), destacando la representación de cánidos a modo de recipientes (Baus Czitrom, 1988; Rodríguez Galicia et al., 2001; Cabrero García \& Valadez Azúa, 2009; Rodríguez Galicia et al., 2012; Cupul Magaña et al., 2014). Ello la postula como como una región donde las prácticas de inhumación conjunta entre perros y humanos cobraron importancia desde tiempos tempranos, práctica que en el Epiclásico (AD 500/600-900) comenzaría a extenderse por el resto de Mesoamérica (Valadez Azúa et al., 1999).

En este sentido, al realizar una revisión de los trabajos previos se saca en claro la sobrerrepresentación de contextos fúnebres en el registro arqueológico (Porter, 1956: 537; Taylor, 1970: 166; Flores, 1992: 15; Cabrero García, 1995: 142; Winning et al., 1996: 413; Carot, 2001: 24; Mountjoy et al., 2014; entre otros), hecho que a nuestro entender motiva una tradición académica de interpretación del perro como elemento psicopompo (Valadez Azúa et al., 2010: 232). Un animal que guía a los difuntos a través de un periplo en el 'más allá', visión deudora de las fuentes etnohistóricas ${ }^{1}$ que recogen información del Postclásico (AD 900 -1552). Sin desestimar este punto, considero que la relevancia de ultratumba con la que se relaciona a los perros es el resultado de un plano de interacción en vida que ha de ser analizado en sus propios términos. El presente trabajo, sumario de más de tres años de trabajo materializados en una tesis de maestría (Brito Mayor, 2017), tiene como objetivo principal la identificación del contexto social en el que se integra el animal, tomando el marco teórico que nos brinda la Zooarqueología Social (Marciniak, 1999; Russell, 2012).

Se gesta a partir de los postulados de la arqueología interpretativa (Hodder, 1991), planteando una perspectiva holística de análisis zooarqueológico que entiende las relaciones entre animales-no humanos y animales-humanos como resultado de una participación inter-especie (Brittain \& Overton, 2013: 137). Pensar en el Homo sapiens como agente único en este complejo me resulta reduccionista en términos generales, con un claro acento sobre su capacidad de influir pero minusvalorando la de ser influido. En este punto se maneja como heurística la zoontología, ejercicio epistemológico

\footnotetext{
1 Desde inicios del contacto se recogen notas sobre el trato distintivo que se les daba a ciertos perros, como se puede ver en Hernán Cortés o Cervantes de Salazar. Pero es sin duda la labor franciscana la que mayor atención prestó sobre los cultos indígenas, destacando referencias como las de Muñoz Camargo (1892 [1576-1591]:61]) y Sahagún. Este último plasma en su Códice Florentino el conocido pasaje en el que nos habla de las prácticas que se llevan a cabo en el tratamiento de los finados. Entre ellas comenta que "Hacían al defuncto llevar consigo un perrito de pelo bermejo [...] y se va a los nueve infiernos, donde está y pasa un río muy ancho, y allí viven y andan perros en la ribera del río [...]. Dicen que el defunto que llega a la ribera del río arriba dicho, luego mira el perro. Si conoce a su amo, luego se echa nadando al río, hacia la otra parte donde está su amo, y le pasa a cuestas. [...] Por esta causa los naturales solían tener y criar los perritos para este efecto" (Sahagún, 1577: libro 3, folio $25 \mathrm{r}-26 \mathrm{r}$ ).
} 


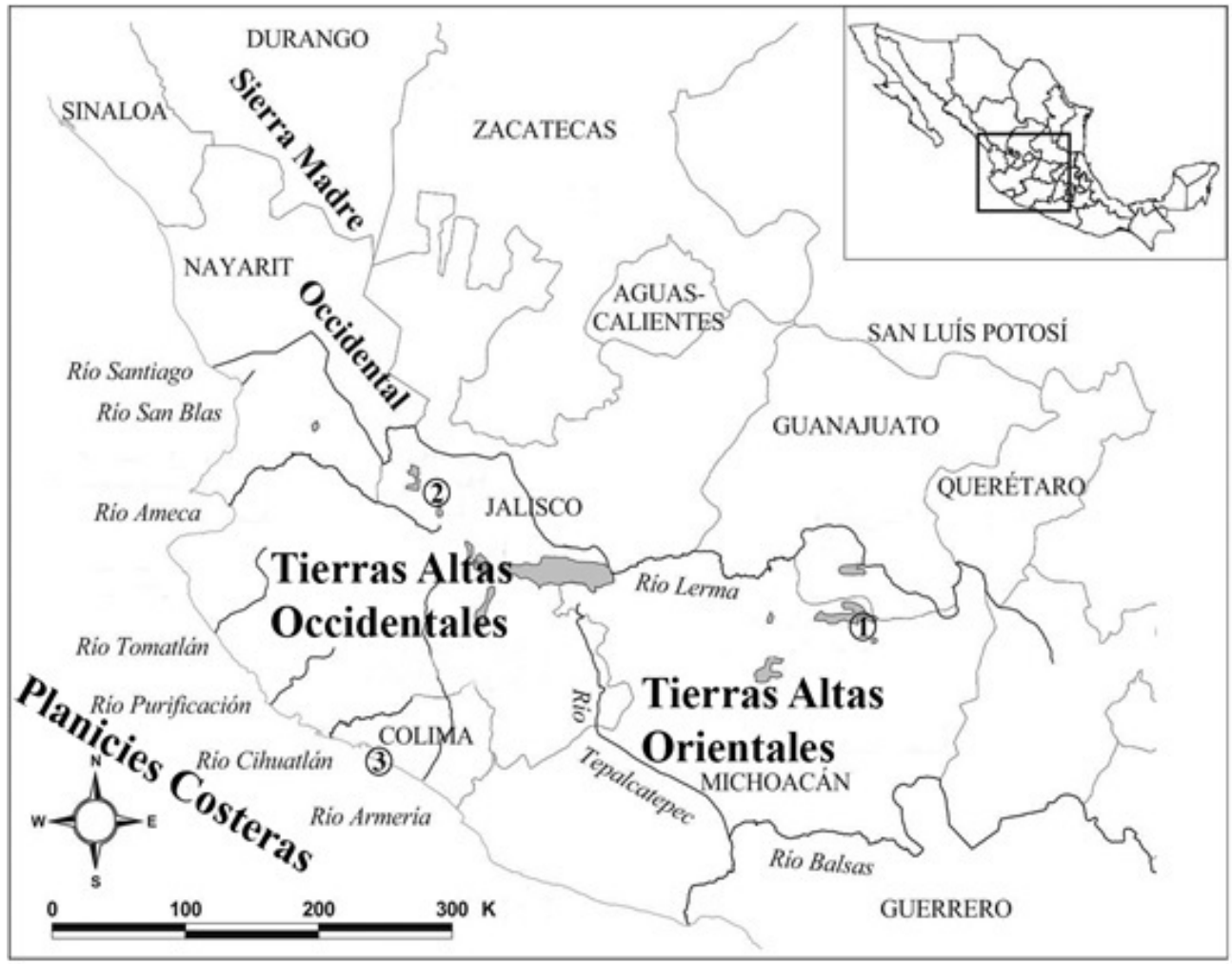

FIGURA 1

Mapa del Occidente de Mesoamérica, donde se señalan las tres de las subáreas que aborda el presente trabajo a través de los estudios de (1) La Mina, (2) Los Guachimontones, (3) Terminal de Gas Natural Licuado Manzanillo y Patio de Maniobras Tepalcates II (Modificado de Beekman, 2010: 42).

que entiende al animal como ente agencial capaz de reconocer su mundo y actuar en consecuencia (Overton \& Hamilakis, 2013: 113).

Atendiendo a la heterogeneidad cultural presente en el Occidente y al desarrollo que presenta la zooarqueología en la región, hemos optado por un modelo de investigación en base a tres estudios de caso, donde fueron encontradas inhumaciones de seres humanos con perros. Considero imprescindible estudiarlas en sus propios términos, analizando los restos óseos mediante la "credibilidad de una observación física mediada" que nos otorgan las aproximaciones actualísticas como fuente de generación de hipótesis (Marciniak, 1999: 303).

Los análisis en La Mina, Los Guachimontones y la Laguna de Cuyutlán (Figura 1) son en base a contextos primarios. Esto otorga una entidad a la interpretación arqueológica, que viene motivada por las siguientes preguntas generales:

¿Qué información sobre el uso social del perro podemos identificar en nuestros estudios de caso? Archaeofauna 28 (2019): 169-184
¿Cómo la entendemos dentro de los contextos sistémicos ${ }^{2}$ que analizamos?

\section{MATERIAL Y MÉTODO}

La investigación en nuestra disciplina parte de bases similares al resto de estudios en las ciencias sociales. Paso ineludible es la tramitación de permisos institucionales, el documentarse en archivos y bibliotecas, así como mantener vínculos con los agentes informantes de primera mano, en nuestro caso arqueólogos responsables de las campañas o custodios de los materiales. Pero más allá de ello,

${ }^{2}$ Retomando el análisis schifferiano para su aplicación en la investigación del pasado mesoamericano se distingue entre contexto arqueológico, que son los restos que nos llegan del contexto sistémico, "el de las sociedades vivas, en operación" (Gándara, 2011: 96). 
los procesos que integran nuestra metodología giran en torno a un discurso transdisciplinario, autocrítica epistemológica que transgrede las fronteras tradicionales erigidas en torno a las distintas ciencias (Nicolescu, 2002). Este ejercicio de colaboración participativa encuentra amparo en el Laboratorio de Paleozoología del IIA-UNAM, núcleo de casi 30 años de investigación en el campo de la zooarqueología de cánidos mesoamericanos (Valadez Azúa et al., 2013: 188).

Durante el trabajo de gabinete la obtención de datos fue organizada sistemáticamente en dos grupos. Por un lado los datos primarios, que con bases en la anatomía comparada ofrecen información taxonómica, sobre el sexo y la edad (Ruscillo, 2003; Hillson, 2005; Blanco Padilla et al., 2009). Es fundamental una descripción minuciosa con la nomenclatura adecuada, la consulta de manuales osteológicos y la utilización de una nutrida colección de referencia. En este nivel de análisis también se pueden detectar indicadores patológicos que hayan quedado registrados en el hueso, como ciertos episodios traumáticos, de estrés nutricional o incluso enfermedades infecciosas (Baker \& Brothwell, 1980). Finalmente se tiene en cuenta la toma potencial de 35 medidas, en base a puntos osteométricos y estándares sancionados (Driesch, 1976; Rodríguez Galicia, 2000; Blanco Padilla et al., 2009).

Los datos secundarios se desprenden de aproximaciones actualísticas y aplicaciones arqueométricas, comenzando a definir una entidad explicativa dentro del contexto de origen de los restos. Las medidas tomadas permiten obtener información biotípica que puede llegar a identificar diferentes morfotipos en el caso de cánidos mesoamericanos (Blanco Padilla et al., 2009). De vital importancia para nuestros fines es la evaluación de la tafonomía y la diagénesis, que realizamos en base a un modelo de análisis multivariado. Se discierne entre las marcas de origen biológico y antrópico, para establecer un orden de afección y obtener una visión cronológica de los procesos "postmortales" que afectaron al hueso (Bar-Oz \& Munro, 2004; Sainz de los Terreros, 2013). Ello nos permite hallar fundamentos de interpretación del contexto arqueológico, además de seleccionar las muestras aptas para formar parte de los análisis arqueométricos.

En este sentido, se posiciona como objetivo de trabajo la determinación de las tendencias paleodietéticas de los perros, concibiendo como supuesto metodológico que la nutrición de los animales do- mésticos está condicionada por variables antrópicas. El análisis de oligoelementos forma parte de los protocolos de estudio de cánidos prehispánicos en el Laboratorio de Paleozoología IIA/UNAM (Valadez Azúa et al., 2005: 950-951). Con la manifiesta intención de aportar en esta línea de estudio, hemos optado por la obtención de datos paleodietéticos mediante el conteo de elementos traza frente a otras opciones. Para ello adecuamos el protocolo de procesado de muestras y lectura de oligoelementos por XRF, incluyendo un amplio repertorio de muestras que comprendió restos humanos y perros arqueológicos junto a especímenes de referencia como pueden ser herbívoros o carnívoros estrictos. La lectura de elementos traza se realizó con el equipo Thermo Scientific ${ }^{\mathrm{TM}}$ Niton $^{\mathrm{TM}}$ XL3t del Laboratorio de Geoquímica Ambiental del IG-UNAM. Los resultados obtenidos en ppm. se comparan en histogramas, prestando especial atención a la relación $\mathrm{Sr} / \mathrm{Zn}$. Por último, motivado por la incertidumbre temporal que algunos contextos suscitaron, se obtuvieron dataciones numéricas por AMS en el Laboratorio Nacional de Espectrometría de Masas con Aceleradores (LEMA) IF-UNAM, calibradas con OxCal 4.3.2 y la curva IntCal 13 en su versión online (Ramsey, 2009; Reimer et al., 2013).

\section{ESTUDIOS DE CASO Y RESULTADOS}

En las Tierras Altas Orientales se emplaza el sitio de La Mina, sobre la orilla sur del Lago de Cuitzeo (Figura 1) (Aguayo Haro \& Quiroz Castañón, 2014). El hallazgo de restos arqueológicos en tareas de cimentación de una barda motivó la intervención del centro INAH Michoacán en diciembre de 2013. Al identificar el carácter fúnebre del conjunto, inserto en una plataforma habitacional, se realizaron dos pozos de excavación en las áreas donde permanecían vestigios in situ (Figura 2). Un total de 5 NMI de Canis familiaris fueron identificados, de los cuales 2 se pudieron estudiar en profundidad. El Pozo Norte se caracterizó por la presencia de inhumaciones primarias, con restos antropológicos y zoológicos en un avanzado estado de degradación. Se identifica el Entierro 1, con dos humanos subadultos en posición fetal y ajuar cerámico. Esta producción dio la pauta para la definición cronológica en torno al Epiclásico, que terminó acotándose por datación arqueomagnética entre AD 647-825 (Goguitchaichvili et al., 2016). Relacionado con 


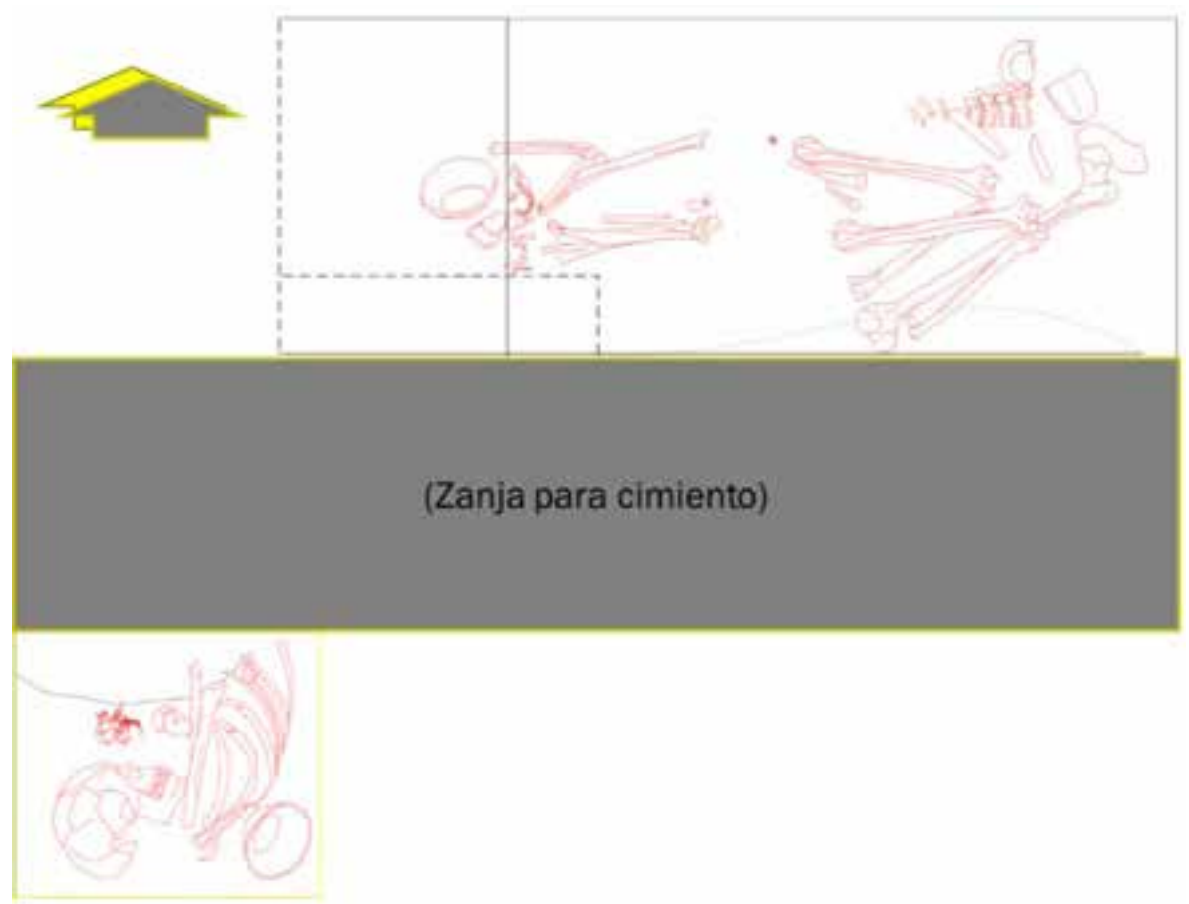

FIGURA 2

Croquis general de la intervención de rescate arqueológico en el sitio de La Mina donde se puede aprecia la estrecha relación entre el Pozo Norte y el Pozo Sur (modificado de Aguayo Haro en Brito Mayor et al., 2017).

este conjunto aparecieron restos óseos de un perro juvenil $^{3}$ semiarticulado, denominado Entierro 1C. Cuenta con signos de coloración diferencial en las regiones óseas más expuestas, como en el borde craneal de la tibia y su diáfisis, a lo que se asocia una pátina brillosa uniforme y una textura pulimentada que suele vincularse con el uso de agua como elemento de trasmisión de calor (Pijoan Aguadé et al., 2010: 165). Otro factor a tener presente es la estrecha vinculación a recipientes intencionalmente fracturados, denominados cerámicas matadas.

En el Pozo Sur afloró el Entierro 1A que pese a estar incompleto permitió estudios detallados, comenzando a ser conocido por el nombre de Álvaro tal como nos referiremos en este escrito. Se trata de un individuo adulto masculino, de entre 30-35 años al momento de su muerte, depositado en decúbito lateral izquierdo flexionado con una orientación SW-N y cuyo análisis odontológico re-

${ }^{3}$ Espécimen juvenil de 8 meses estimado por desarrollo óseo (vértebras lumbares fusionadas en cuerpo y apófisis y epífisis distal de húmero derecho sin fusionar) con $28.88 \mathrm{~cm}$. a la cruz (calculado por longitud de la tibia izquierda: $99.57 \mathrm{~mm}$.) vela interesantes prácticas (Aguayo Haro \& Quiroz Castañón, en preparación). Salve destacar que posee una modificación intencional de los incisivos y caninos de ambas arcadas (Figura 3). Le acompañan dos elementos: un cajete a su espalda y unos restos de cánido en conexión anatómica a la altura de la cara del individuo, que estaban rodeados por su brazo. El cachorro ${ }^{4}$ fue depositado en decúbito prono con las extremidades desfasadas y la cabeza girada hacia la derecha. Se registraron cambios de coloración café-rojizo en las partes de los huesos más expuestos, es decir, en contacto directo con la piel. Ello motivó la comparación y mapeo de estas evidencias (Figura 4), examen que derivó en su identificación como alteraciones térmicas directas que evidencian la exposición del cuerpo a una fuente de calor plana durante un tiempo no superior a 10 minutos (Pijoan Aguadé et al., 2010). Es sin duda en el esqueleto craneal donde aparecen

\footnotetext{
${ }^{4}$ Espécimen cachorro de 3 meses estimado por crecimiento dental (se aprecia cavidad de M/1 aun sin eclosionar) y $13,50 \mathrm{~cm}$ de alzada mínima (calculada por la longitud del húmero izquierdo sin epífisis: $42.26 \mathrm{~mm}$ ).
} 

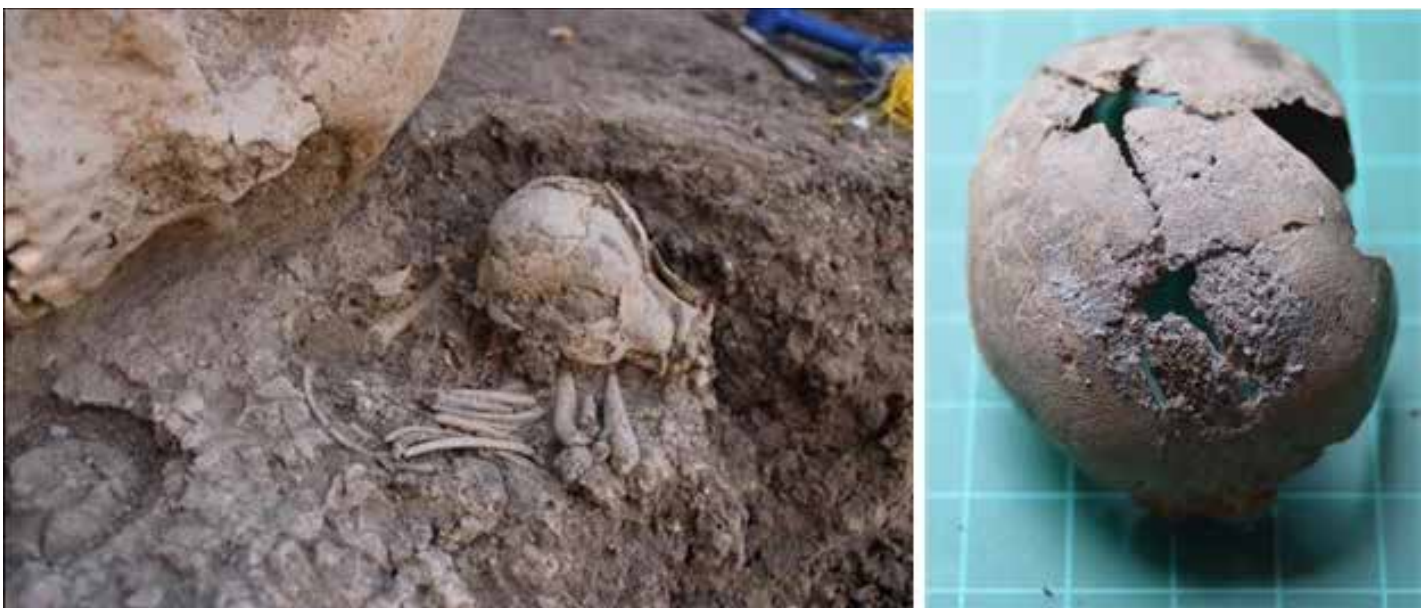

FIGURA 3

(Izquierda) Contexto original del Entierro 1A con su cachorro y (derecha) traumatismo.

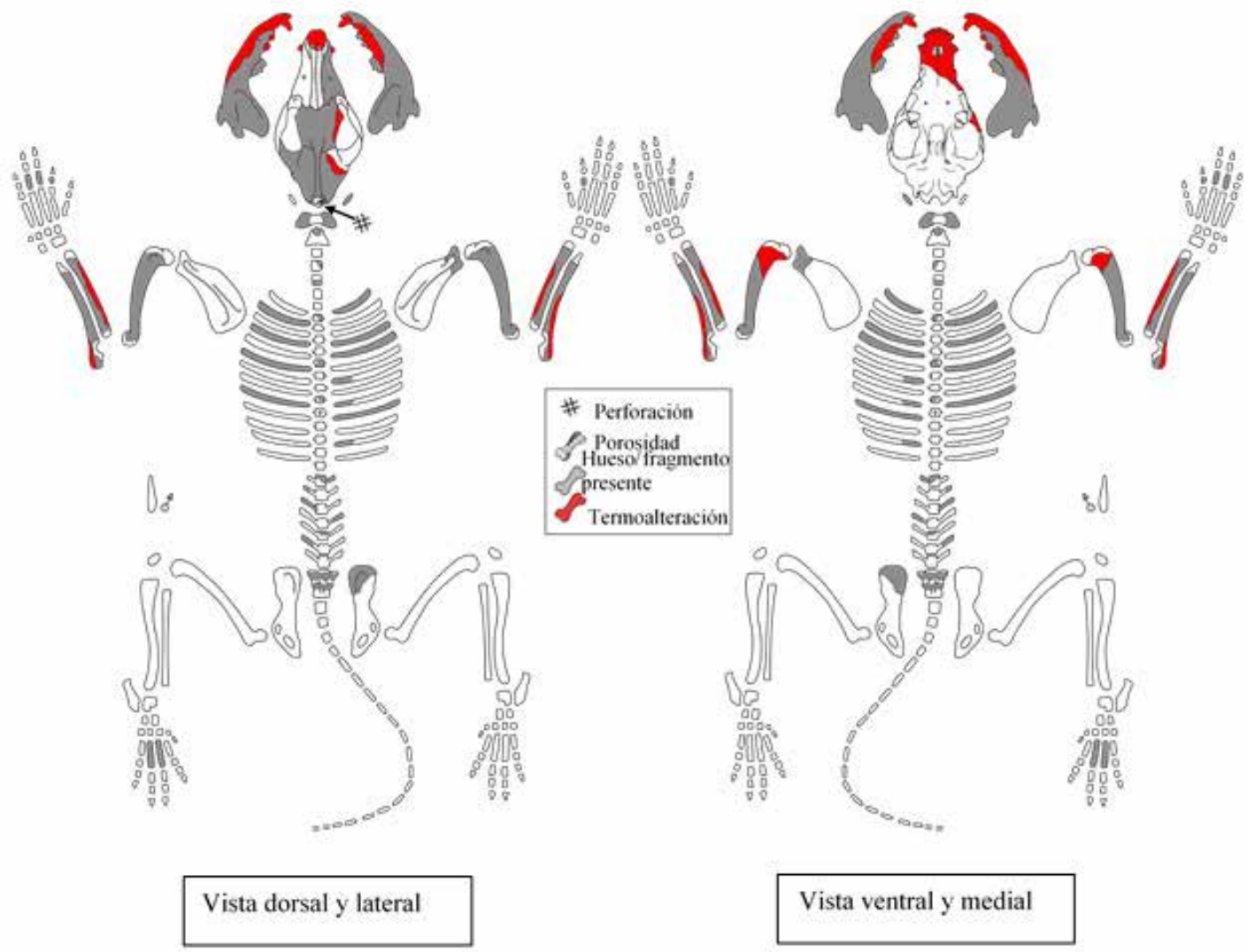

Restrence :

Dessin vectoriel par Mchel Coutureau (Inrap) - O 2013 ArcheoZococe

Dapres : Daniel Helmer - Fiches descriptives pour les relevés densembles osseux animaux.

in : Jean Desse et Nathale Desso-8erset (dz.) - Fiches dostelogie animale pour farchtologie, Serie B: mammiteres, $n^{*} 1$

Juanies Pins : Centre de recherches archeologiques du CNRS I APOCA. 1987, to. 1

FIGURA 4

Ficha Helmer con los elementos óseos del Canis familiaris del Entierro 1A analizados. 
las evidencias más claras de esta termoalteración, con regiones ennegrecidas en el temporal derecho, en la parte externa de ambas mandíbulas y dientes, presentando una fractura longitudinal uno de ellos. De igual forma, en la parte anterior del neurocráneo se localiza un traumatismo, vinculado a grietas en hueso fresco originadas a raíz de una perforación rectangular (Figura 3). Anexa se encuentra una zona circundante con afección tafonómica diferencial, destacando la porosidad y la reducción de la capa cortical.

La comparación de los niveles de $\mathrm{Zn} / \mathrm{Sr}$ nos permite caracterizar una tendencia alimenticia en humanos ligada a la ingesta de vegetales con poca variabilidad, a excepción del caso del Entierro 1, que se posiciona en lo alto de la tabla evidenciando un mayor aporte de proteína animal (Figura 5). También vinculados a esta tendencia encontramos a los cinco perros muestreados, aunque su dieta cuenta con índices de Sr superiores, lo que suele vincularse con una mayor variabilidad vegetal y aporte episódico de proteína animal. Debido a que la mayoría de los especímenes son subadultos, no podemos evaluar si el distanciamiento que presentan con respecto a los humanos y a los dos perros adultos refleja tendencias dietéticas distintas o si es fruto de la inmadurez del tejido óseo. En este sentido resulta llamativo el caso de Álvaro y las dos muestras tomadas a su cachorro, situados ambos individuos en regiones de la tabla diametralmente opuestas.

Nuestro segundo caso de estudio se ubica en el sitio de Los Guachimontones (Figura 1), enmarcado en un rico entorno ambiental con abundantes recursos lacustres y fuentes de obsidiana, lo que favoreció que se convirtiese en una urbe neurálgica para el Formativo terminal y el Clásico temprano (BC 100-AD 250). Sin embargo, los restos óseos preservados son muy escasos, entre los que identifiqué un total de 4 NMI adscritos a Canis familiaris, de los que sólo 1 pudo ser analizado en profundidad. Se halló en el complejo ceremonial

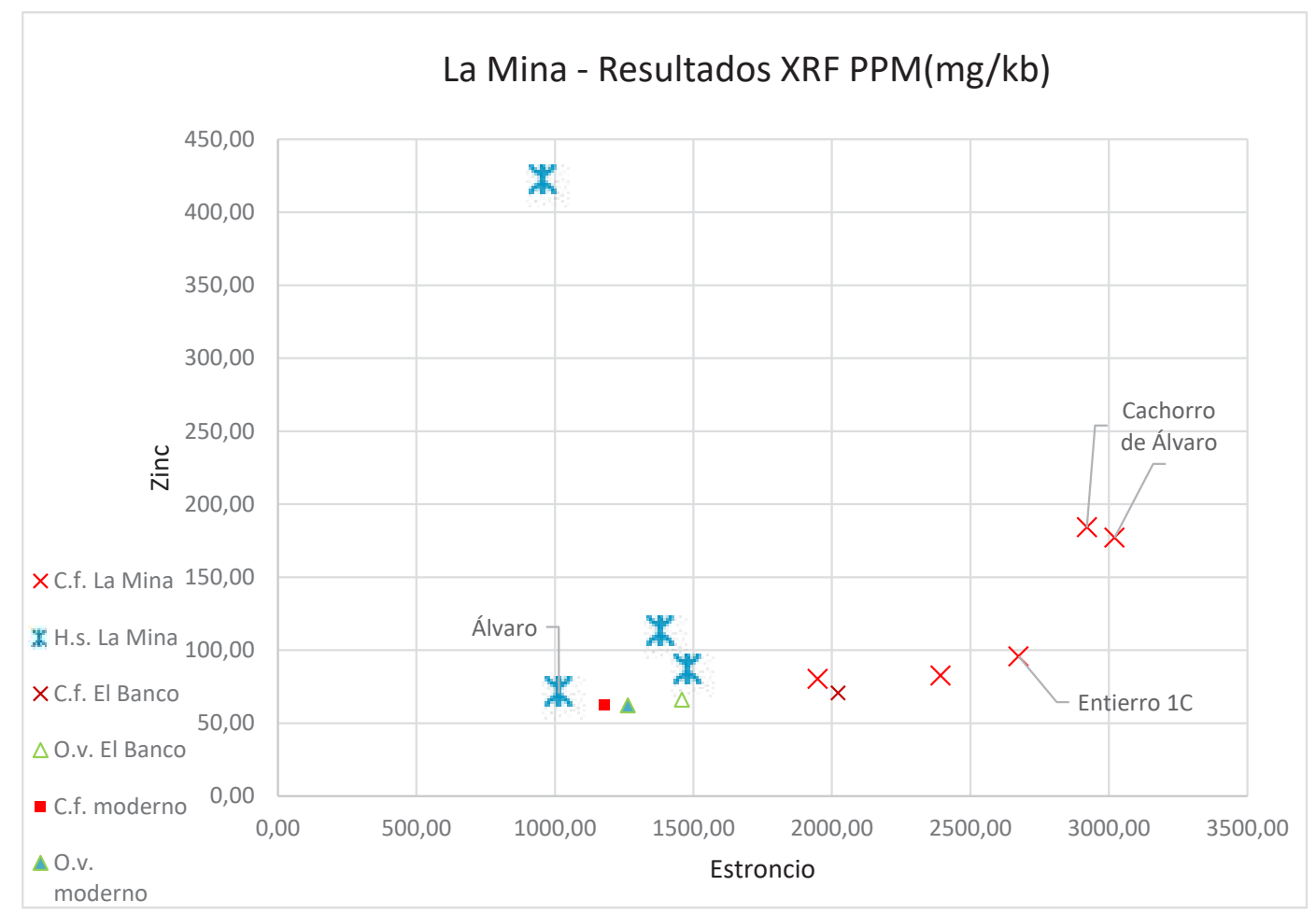

FIGURA 5

El análisis se realizó sobre 6 muestras de cánidos domésticos y 4 de humanos, contrastadas con un herbívoro estricto y un perro del cercano sitio arqueológico El Banco, así como con otro perro y otro herbívoro estricto modernos hallados en la misma zona. Además, se evalua los niveles en 3 muestras de sedimento cuyos resultados de Sr fluctúan entre 408.28-541.97 ppm y de Zn entre 57.39-64.94 ppm., descartándolo como fuente de contaminantes por procesos diagenéticos. 
principal, caracterizado por una serie de estructuras piramidales circulares rodeadas por plataformas rectangulares y recintos abiertos (Weigand \& Esparza López, 2008). Es justamente en uno de ellos, la Plaza Exterior del Círculo 3, donde se ubicaron una serie de inhumaciones relacionadas con una estructura exenta a modo de altar. La Tumba 1 la integra un humano de 6 a 7 años y la Tumba 3 un subadulto de 12 años con un individuo desarticulado sobre él. La particularidad de este último es que presenta deformación craneal y problemas en la mandíbula. En la Tumba 2 también encontramos restos desmembrados de dos individuos, uno con evidencias de gigantismo y otro con cuello corto o síndrome de Klippel Feil (Betancourt López, 2013).

En inhumación individual a menor profundidad pero vinculado al contexto anterior, se encuentra la denominada Tumba 4, un Canis familiaris depositado en decúbito lateral izquierdo de forma que se dibujan los límites de una fosa circular (Figura 6). En el marco de esta investigación lo sometimos a una datación de ${ }^{14} \mathrm{C}$ por AMS que lo ubica temporalmente en torno al Formativo terminal ${ }^{5}$, cons-

${ }^{5}$ LEMA 784.1.1: $1982 \pm 30$ B.P., cal 46 B.C.-76 A.D. (2б). Utilizando colágeno ultrafiltrado, $\delta{ }^{13} \mathrm{C}:-13$. tituyendo así el perro más antiguo del Occidente mesoamericano adscrito por datación numérica hasta el momento. Se trata de una hembra adulta joven ${ }^{6}$, con varios eventos de parto a juzgar por el desarrollo de la sínfisis púbica tal como indica la Biol. Jardón Nava (2004). A nivel dental, este espécimen muestra un avanzado desgaste oclusal, especialmente pronunciado en la parte derecha de la arcada a nivel de los carnaciales. También presenta una caries de fisura en el M/1 de mandíbula izquierda y la pérdida de varias piezas, a las que le siguen eventos de reabsorción de los alveolos. En este sentido se documenta la ausencia del I3 izquierdo de maxilar, seguido de un evento que desencadenó la pérdida de tejido óseo, la expansión de las corticales y el desplazamiento de las piezas dentales adyacentes (Figura 6).

Con todo, la comparación entre $\mathrm{Zn} / \mathrm{Sr}$ refleja en los cuatro cánidos domésticos una dieta dominada por la ingesta de vegetales, pero con mayor variabilidad que en los humanos (Figura 7). Este grupo

${ }^{6}$ Espécimen adulto joven de más de 5 años (estimado por el desgaste oclusal), de sexo femenino estimado por morfología pélvica (diámetro del acetábulo reducido, borde del isquion amplio y apertura pélvica de $107.0^{\circ}$.) y $40 \mathrm{~cm}$ a la cruz (calculada por la longitud del húmero derecho: $129.1 \mathrm{~mm}$ ).

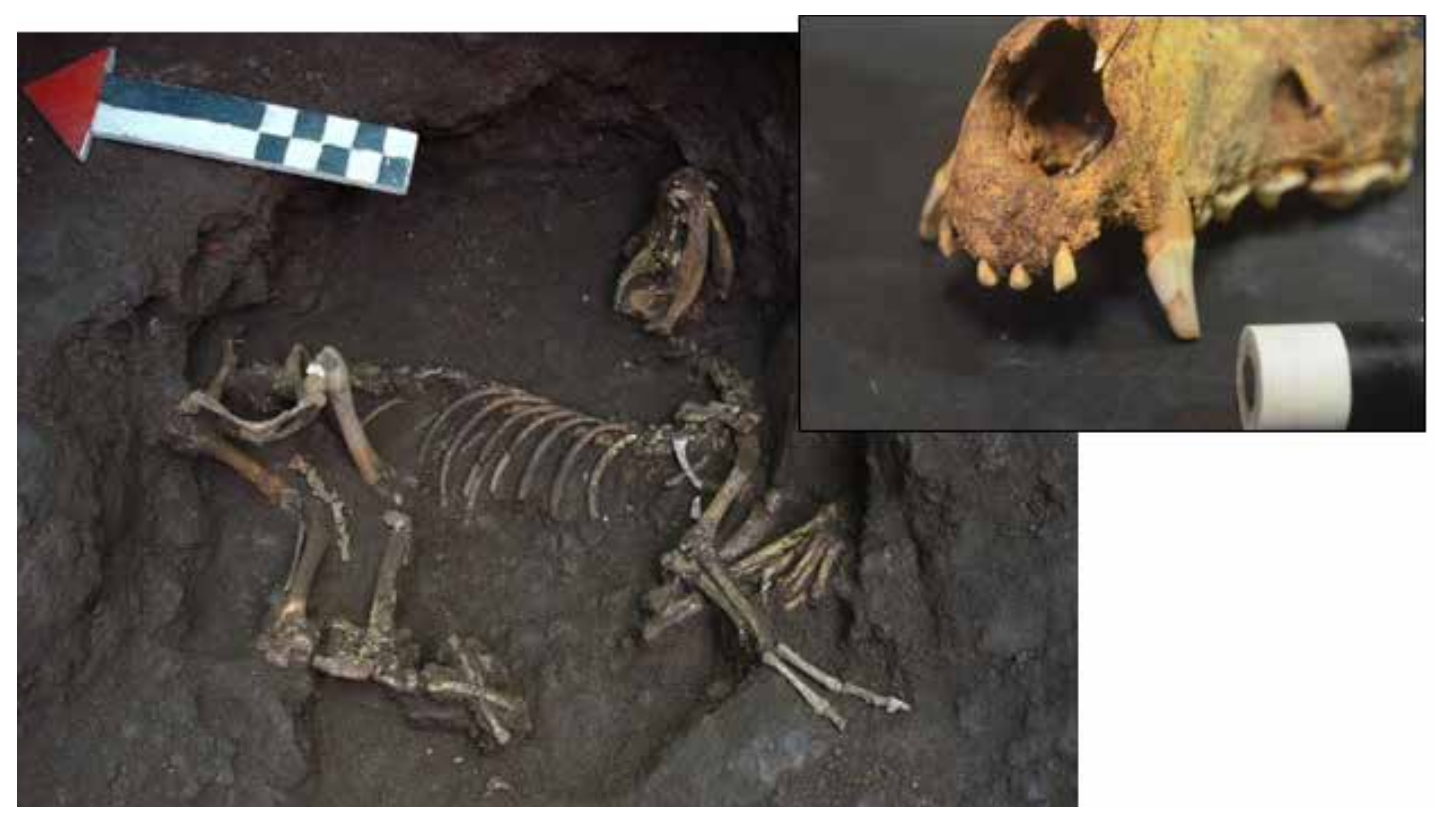

FIGURA 6

(Izquierda) Contexto primario de la Tumba 4 y (arriba) detalle de la afección en el vómer. 


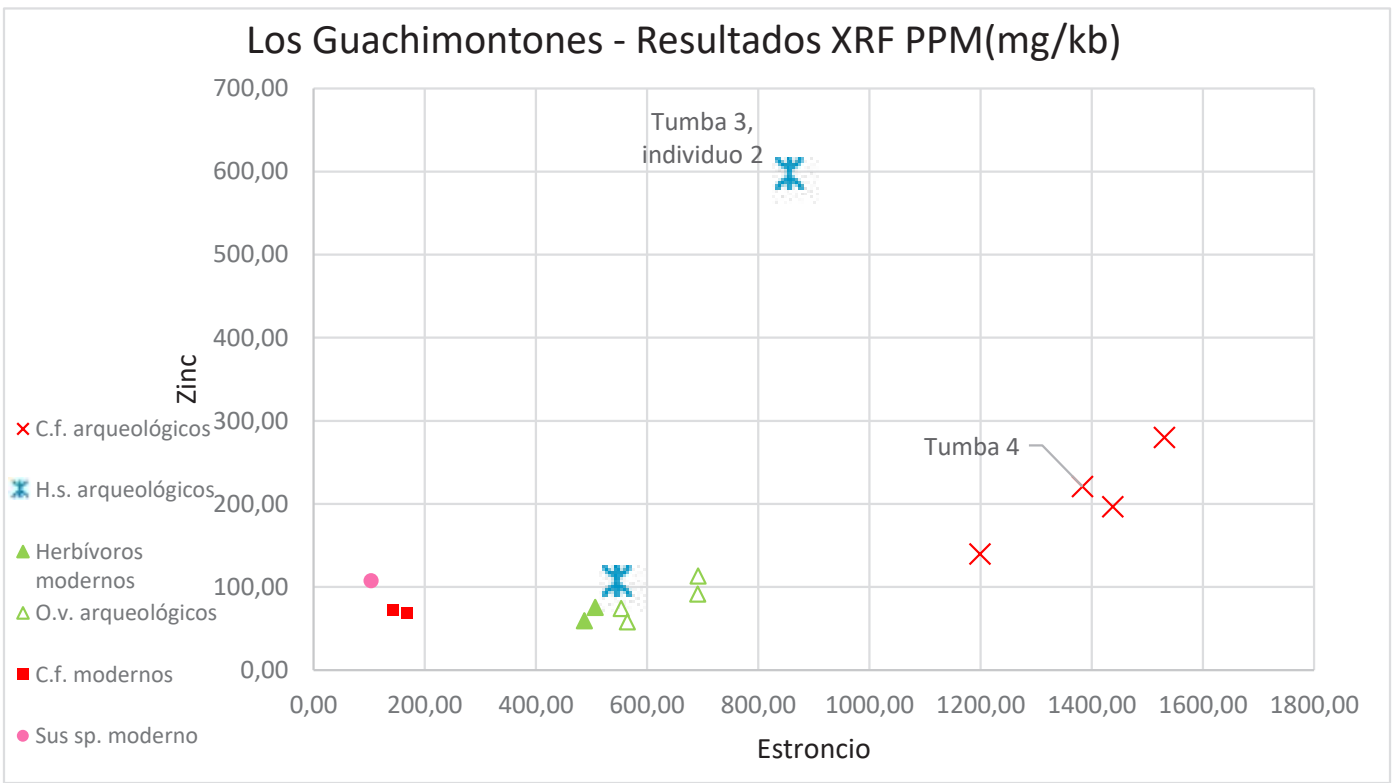

FIGURA 7

El análisis se realizó sobre los 4 perros identificados en el sitio, además de 2 humanos relacionados con estos animales. Con fines de contrastación se tomaron datos de herbívoros estrictos, 4 venados (Odicoileus virginianus) de contexto arqueológico, otro moderno, un caballo (Equus sp.), un cochino (Sus sp.) como representación omnívora y dos perros actuales. Además, se evalua los niveles en 5 muestras de sedimento cuyos resultados de Sr fluctúan entre 78.44-183.76 ppm y de Zn entre 68.55-93.77 ppm., descartándolo como fuente de contaminantes por procesos diagenéticos.

no puede ser analizado por la falta de datos, con solo dos individuos muestreados que reflejan dos tendencias contrapuestas.

Nuestro tercer caso de estudio se encuentra en las Planicies costeras (Figura 1), concretamente sobre la barra arenosa de la Laguna de Cuyutlán, cuerpo de agua salino emplazado en Manzanillo (Colima). La presión antrópica que sufre el entorno, como consecuencia de la industria gasífera, derivó en la actuación de la Dirección de Salvamento Arqueológico del INAH, garantizando la salvaguarda de los vestigios que afloraron. Dos son los sitios que hemos analizado, La Terminal de Gas Natural Licuado Manzanillo (TGNLM) y el Patio de Maniobras Tepalcates II (PMTII), ambos caracterizados por la abundancia de restos de actividades fúnebres ritualizadas. La agresividad de esta matriz sedimentaria, aunado a las fluctuaciones del nivel freático y a la actividad humana reciente, afectaron gravemente al estado en el que se hallaron los restos óseos. Sin embargo, la amplia muestra abarcó una dilatada cronología localmente definida, hilo conductor del análisis de este estudio de caso.

Los restos más antiguos pertenecen a la fase Ortices-Comala (BC 300 al AD 500), con 70 en- tierros humanos localizados en la TGNLM, una Loma Funeraria artificial con un altar central de tendencia circular (Figura 8). Precisamente este periodo se destaca por la fina técnica alfarera y el logro estético en la representación de figuras huecas de cánidos. De esta temporalidad analizamos restos de perros pertenecientes a 8 NMI, 6 de los cuales se hallaron en depósitos conjuntos con otros animales, frecuentemente restos termoalterados de ictiofauna y cocodrilo. Un par de excepciones son dignas de mencionar, como el Ent.584 de un perro adulto de patas cortas o tlachichi ${ }^{7}$, con las extremidades delanteras extendidas al frente del individuo, lo que puede indicarnos un estado inhumatorio en rigor mortis o un determinado acomodo perimortem. Por otro lado, el Ent.569, de humano y restos de cánido adulto masculino desarticulados, con evidencias de termoalteración.

\footnotetext{
${ }^{7}$ Espécimen adulto, posiblemente de patas cortas o tlachichi (Blanco Padilla et al., 2009: 131-161). La longitud máxima de las extremidades delanteras estiradas es de unos $30 \mathrm{~cm}$ (epífisis proximal de húmero dcho.-epífisis distal de falanges medias dcho.) y la longitud cabeza tronco: 1,40 m
} 


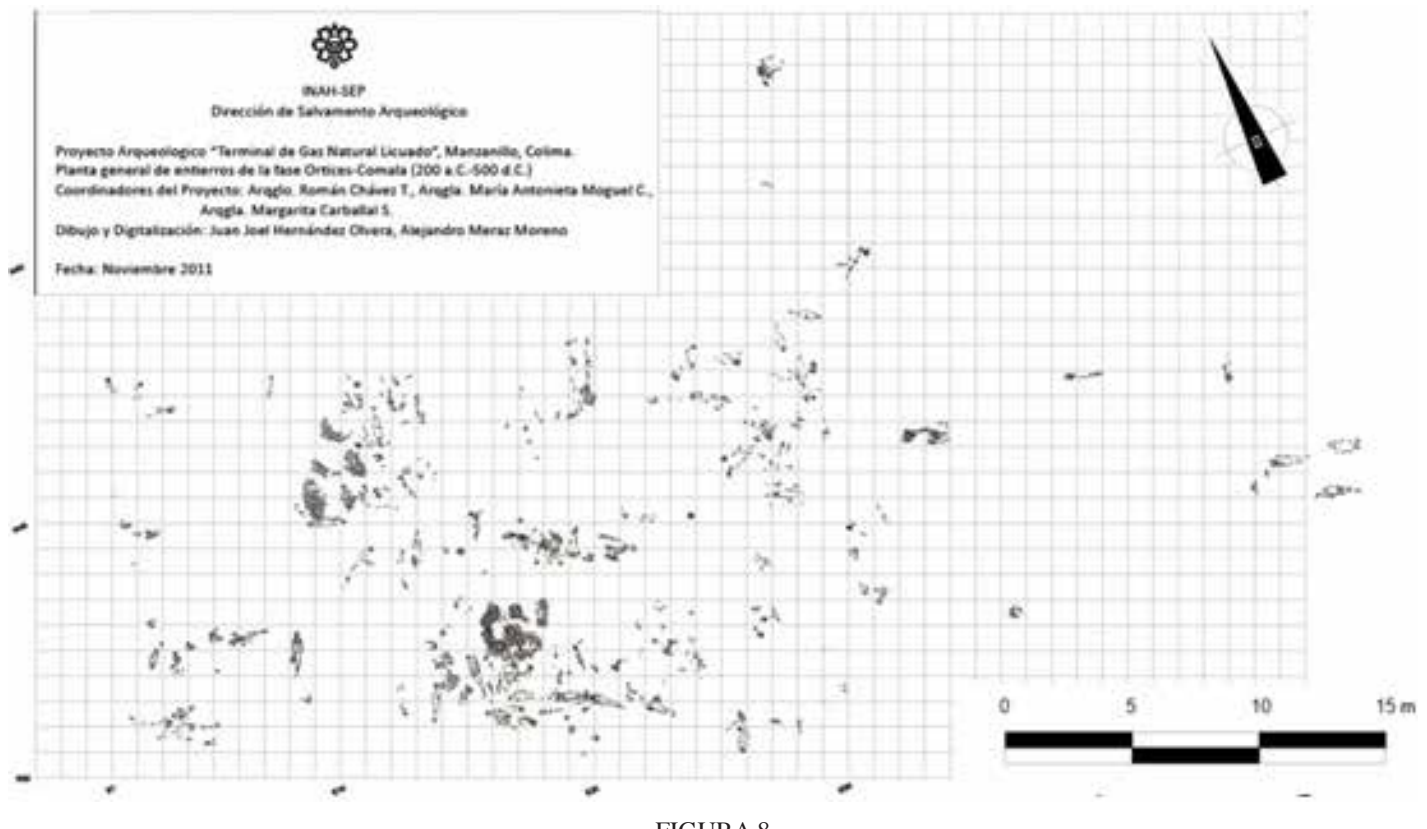

FIGURA 8

Planta general de entierros en la Loma Funeraria de TGNLM (Modificado de Hernández Olvera et al., 2012).

La siguiente fase es la Colima-Armería (AD 550 -900), que parece coincidir con la restructuración del altar central de la Loma Funeraria en forma cuadrangular. 71 entierros humanos quedaron adscritos a esta temporalidad, con tendencias decúbito supino y ofrendas con elementos exógenos de carácter suntuario. Los entierros de perros y humanos se vuelven más frecuentes en este intervalo, pero el estado de los restos no permitió análisis profundos de los materiales que llegaron al laboratorio. Un total de 10 NMI de Canis familiaris pudieron registrarse, entre los que cabe mencionar el Ent.534, el que mejores condiciones de conservación tuvo. Se trata de una inhumación simple de un perro adulto joven ${ }^{8}$ en decúbito lateral derecho con orientación W-E. Se encuentra flexionado de tal forma que se dibujan los límites de una fosa rectangular, que funcionó a modo de contención pasiva del depósito. Una datación por AMS desarrollada en el marco de la presente investigación confirmó la temporalidad Armería9.

Pero sin duda un espacio que destaca en cuanto a los entierros de perros y humanos es el PMTII,

\footnotetext{
${ }^{8}$ Espécimen adulto joven de entre 1 y 2 años (estimado por el desgaste oclusal) y $32 \mathrm{~cm}$ a la cruz (calculada por la longitud del húmero izquierdo: $105.8 \mathrm{~mm}$ ).

${ }^{9}$ LEMA 802.1.2: $1407 \pm 35$ B.P., cal 579 A.D.-669 A.D. (2б). Utilizando colágeno total, $\delta{ }^{13} \mathrm{C}:-20$.
}

que estuvo habitado durante la fase Colima-Armería (AD 550-900), misma que la vista para la TGNLM. Se trata de un espacio residencial denominado Chocohuistle, con un total de 53 enterramientos en el subsuelo, 28 humanos y 25 animales (Figura 9). Existe un claro patrón de deposición en decúbito supino orientado E-W, con ofrenda cerámica medial-capital y figurillas Armería en torno a la pelvis. Además, el desplazamiento óseo postmortem evidencia la existencia de un elemento de contención activa. En los humanos las epífisis distales de los húmeros quedan presionadas hacia las costillas, las epífisis distales de los fémures convergen y los metatarsos se llegan a encimar, además de que las clavículas quedan desfasadas o desarticuladas. Esta pauta se ve también en los perros, cuyas extremidades aparecen hiperflexionadas y pegadas a la caja toráxica, y la cabeza retraída o ladeada. De entre los entierros de animales se documentan 23 perros en campo, 20 de los cuales pudieron ser integrados al presente estudio. Doce entierros simples fueron identificados, destacando el Ent.45 en decúbito supino con las extremidades cruzadas y la cabeza presionada hacia la escápula izquierda, indicadores de presión activa. Esto parece ser una constante, manifestada también en inhumaciones conjuntas, como el Ent.52 y el Ent.53. Este último es un perro adulto joven que muestra una perforación de factura antrópica en el calcáneo derecho 


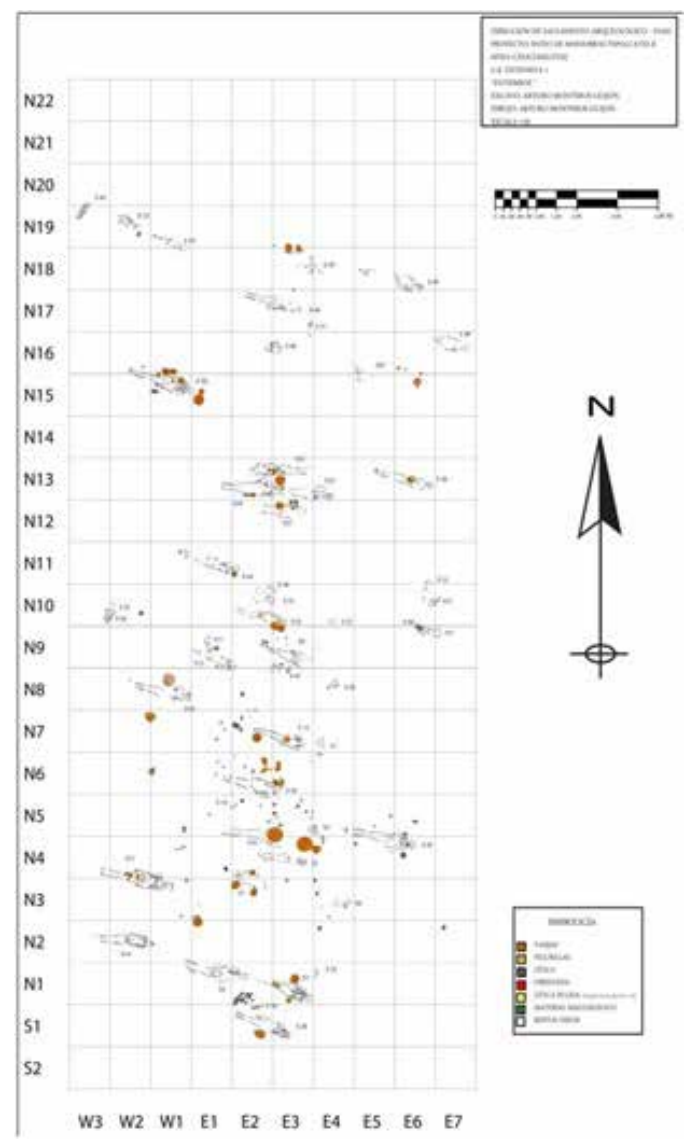

FIGURA 9

Planta general de entierros en la Extensiva 1 del Pozo 22 (Monteros Guijón, 2011: 6).

coincidente con la intersección de sus patas cruzadas (Figura 10). También lo vemos en los entierros conjuntos, como el del Ent.8 protagonizado por una mujer adulta con un perro adulto joven ${ }^{10}$ sobre su pierna izquierda, ambos con signos de contención activa pese a su mal estado de conservación. Sobre este perro se realizó una datación por AMS que arroja resultados discordantes con el contexto general ${ }^{11}$. Los resultados del análisis arrojan una ínfima cantidad de colágeno residual contenida en esa muestra, que obligó a combinar el colágeno mayor a $30 \mathrm{KDa}$ y el menor a $30 \mathrm{KDa}$, pequeñas porciones

${ }^{10}$ Espécimen Ent.9 adulto joven (estimado por el desgaste oclusal) de $25 \mathrm{~cm}$ de alzada mínima (calculado por la longitud de la tibia sin epífisis: $87.04 \mathrm{~mm}$ ).

11 LEMA 801.1.2: $377 \pm 30$ B.P., cal 1445 A.D.-1633 A.D. $(2 \sigma)$. Utilizando colágeno total, $\delta{ }^{13} \mathrm{C}:-19$ de colágeno que resultan de la degradación y son más susceptibles de contaminarse. Esto podría tener como consecuencia que la edad sea mayor que la esperada. Tal parece ser el caso de acuerdo con las estimaciones de las responsables del proyecto, que acotan el intervalo temporal del depósito por la producción cerámica que en el mismo se inserta ${ }^{12}$. En la base del mismo depósito del Ent.8, junto a un pulidor basáltico, se encuentra dos especímenes en muy mal estado, el Ent.10 de perro adulto maduro y el Ent.15. al sur del conjunto.

Como hemos apuntado, tanto en la TGNLM como en PMTII se valora un mal estado de conservación de los restos óseos, debido principalmente a la agresividad del contexto que los alojaba. Su emplazamiento en una barra arenosa de laguna le confiere una matriz abrasiva, dinámica y salina, a la merced de fluctuaciones freáticas y procesos litorales adversos. Sumado esto a la actividad radicular de los recientes cultivos de cocoteros y la presión antrópica sobre una excelente vía de comunicación, el potencial de afección al estado en el que se hallaron los restos óseos resulta factible. Con el fin de evaluar este tipo de injerencia en la nitidez de nuestros datos, sometimos a análisis un total de 8 muestras de sedimento. Los resultados que reflejan son muy similares a los obtenidos en las piezas óseas, dato que vemos como posible evidencia de un avanzado proceso diagenético. A ello se aúna que las tendencias generales que se muestran en el gráfico quedan poco definidas (Figura 11), lo que no nos permiten interpretarlas con garantías de estar reflejando información paleodietética.

\section{DISCUSIÓN}

En orden cronológico, la primera etapa de la Loma funeraria de TGNLM es la que aparece, dentro del marco local Ortices-Comala (BC 300 al AD 500). Correspondería al Formativo terminal y al Clásico, margen en el que 6 de los 8 NMI parecen fungir un papel vinculado al de ofrenda alimenticia, manifestada en depósitos conjuntos con otros animales termoalterados. Coetáneamente atende-

\footnotetext{
${ }^{12}$ Se encuentra en proceso de redacción una publicación académica que pone en concordancia las presentes dataciones numéricas con el contexto de origen y el rendimiento de colágeno de cada una de las muestras.
} 

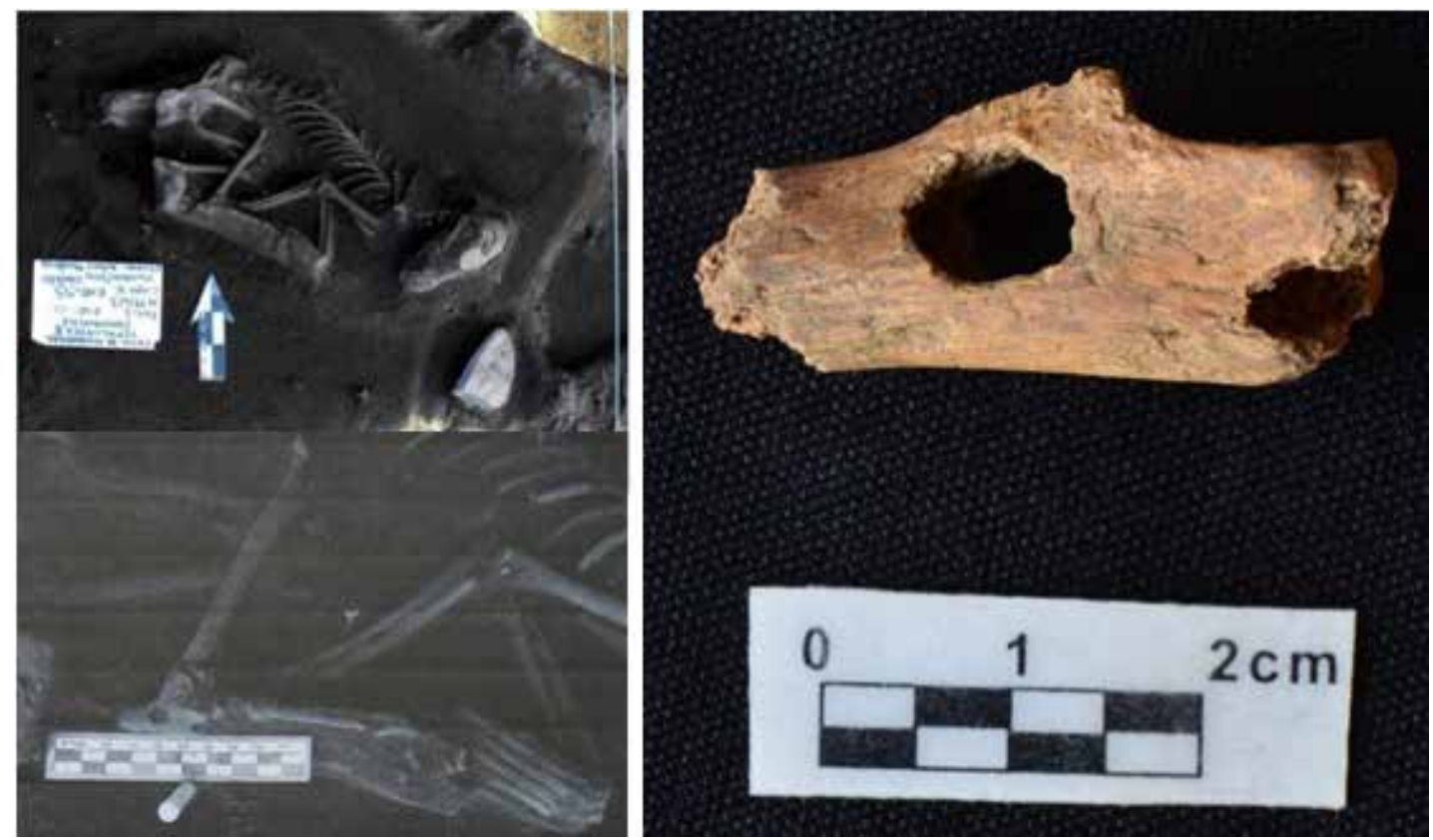

FIGURA 10

Izq. Fotografía en campo con detalle en el que se aprecia la perforación a nivel del calcáneo derecho el Ent.53 (Facilitada por la Mtra. Margarita Carballal); Drch. Detalle del orificio.

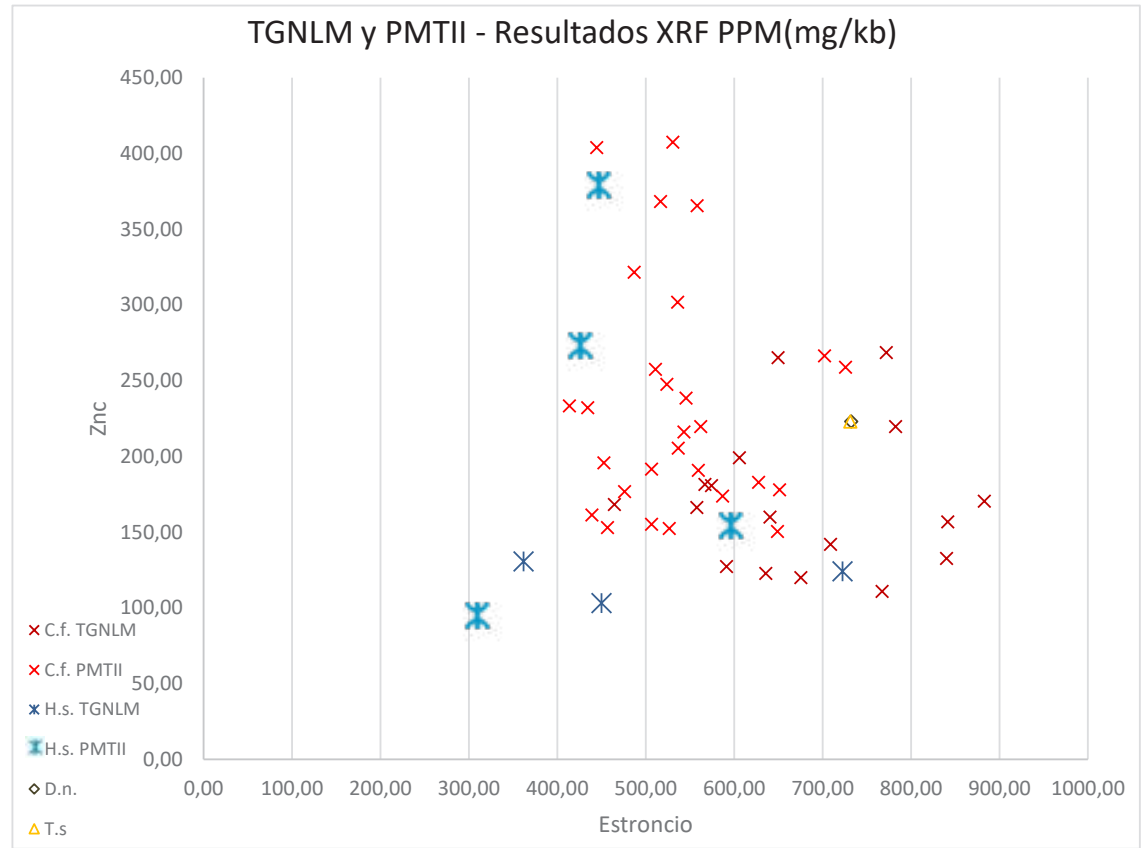

FIGURA 11

El análisis de elementos traza se realizó en base a muestras de 3 humanos y 17 perros de la TGNLM, junto con 4 humanos y 28 cánidos domésticos de PMTII. En este sentido también se incluyó una muestra de armadillo (Dasypus novemcinctus) y pecarí (Tayassuidae), animales con tendencias omnívoras. Se evaluan los niveles de 8 muestras de sedimentos cuyos resultados de Sr fluctúan entre 368.91 -466.33 ppm y de Zn entre 69.67-133.47 ppm., postulando la matriz como fuente de contaminantes por procesos diagenéticos. 
mos a un fenómeno distinto, ubicado en el corazón de las Tierras Altas Occidentales, donde se identifican sinergias poblacionales que giran en torno al sitio Los Guachimontones. Nos hemos centrado en los depósitos fúnebres de la Plaza Exterior del Círculo 3, caracterizados por la presencia de individuos en posición secundaria con rasgos patológicos que se manifiestan físicamente. A este espacio pertenece la Tumba 4, una perra de unos 5 años, 40 $\mathrm{cm}$ de alzada, multípara y con un singular historial odontológico. Un avanzado proceso infeccioso, como resultado de una posible osteomielitis exógena maxilofacial, es decir, una infección originada en el tejido próximo al vómer que termina por afectarlo (Figura 6). Esto le causó una modificación facial, a lo que pudo ir sumado una protución lingual episódica. Atendemos aquí a un fenómeno en el que los humanos y la perra tienen en común características que los hacen dispares desde un plano empíricamente observable. Por lo tanto, se abre la posibilidad de que estemos hablando de una práctica propiciatoria o votiva en torno a lo fúnebre, donde el animal-humano y el animal-no humano participan de atributos similares. En este sentido resulta clarificador ver los desarrollos de este fenómeno en su marco geográfico inmediato, donde hallamos la Cultura Bolaños de mediados del Clásico. En particular en el sitio de Pochotitan se documentan 6 NMI biométricamente similares a la perra que hemos estudiado. Estos especímenes aparecieron en depósitos añexos a los círculos ceremoniales y se interpretan como eventos periódicos de protección del espacio, en una sociedad en la que su papel en la caza sería fundamental $(\mathrm{Ca}-$ brero García \& Valadez Azúa, 2009: 92; Rodríguez Galicia et al., 2012: 209).

Volviendo a la Tumba 4, la afección bucal de la perra derivó en una mecánica masticatoria adaptada, que se ve reflejada en un patrón diferencial de desgaste. Pero, a la luz de los datos paleodietéticos, esto no afectó a su alimentación que se enmarca en la misma pauta que la del resto de perros de Los Guachimontones (Figura 7). Una nutrición en base a una ingesta vegetal con alta variabilidad y aporte episódico de proteína animal. Idéntico patrón arrojan los resultados de los dos depósitos del caso de La Mina, siguiente en la escala cronológica al adentrarse en el Epiclásico (AD 500/600-900). Por un lado, el Entierro 1C, integrado por un perro juvenil de 8 meses con evidencias de termoalteración indirecta por hervido. Por el otro, el Entierro de Álvaro acompañado por un cachorro de 3 meses que presenta una termoalteración directa generalizada con un patrón de exposición a una fuente de calor plana (Figura 4). Tras su análisis se saca en claro que la forma en la que se le expuso fue decúbito prono con las extremidades desfasadas como si estuviera abierto en canal, misma posición en la que se inhumó. Este individuo cuenta con una perforación de sección rectangular en la intersección entre los parietales y el occipital, conocida como punto Lambda. Se plantea como hipótesis de trabajo su origen antrópico, a modo de traumatismo ejecutado previo a la termoalteración. Con todo, en este punto concluyo que la función inmediata del perro se figura como ofrenda alimenticia con elementos que hacen pensar en fines que trascienden la satisfacción de necesidades nutricionales. Abonando este campo puede entenderse la modificación dental de Álvaro como reflejo la forma de "flor de lis", característica de los incisivos de los cánidos (Valadez Azúa et al., 2004; Montiel Mendoza et al., 2008). En la misma línea pueden entenderse la termoalteración como parte de ritual funerario, la vinculación de "cerámicas matadas" o el propio empleo de especímenes inmaduros.

Volviendo a los contextos de las Planicies costeras llegamos al límite superior de alcance de nuestro análisis, el final del Epiclásico. En la TGNLM se identifica no solo un cambio en el área de utilización de la Loma sino una reestructuración cuadrangular del altar central. La tendencia de deposición de entierros es en decúbito supino, con ofrenda capital y figurilla antropomorfa sobre el tórax o pelvis. De igual manera, el sitio presenta elementos exógenos en el ajuar e indicadores que relacionan el espacio con su utilización por parte de una clase empoderada, en una sociedad marcadamente estratificada. La tendencia generalizada de la fase anterior parece tener continuidad. Es decir, depósitos conjuntos de animales, y representación de partes cuando acompañan al humano. Esto contrasta con el cercano asentamiento Chocohuistle identificado en PMTII, un espacio coetáneo al anterior pero en el que convive la actividad residencial y la de orientación fúnebre, realizada en el subsuelo. Se documenta un patrón de inhumación en decúbito supino con orientación E-W, ofrenda cerámica medial-capital y figurillas antropomorfas en torno a la pelvis. Además, la forma en la que se encontraron los individuos evidencia la utilización de elementos de contención activa como parte del ritual funerario, también aplicada a los cánidos. Una suerte de fardo textil que no sobrevivió al deterioro natural 
de los elementos orgánicos (Cuevas Sagardi et al., 2013: 34). Vemos aquí dos prácticas distintas, pero que confluyen temporal y espacialmente sobre la barra de la Laguna. Por un lado, la participación de perros en eventos de comidas rituales vinculadas a un espacio fúnebre, utilizado por algunos miembros de una sociedad estratificada con acceso a elementos exógenos. Por el otro, el sitio de Chocohuistle con gran cantidad de perros enterrados, en similares condiciones a las que presentan los humanos. Una diferencia tan marcada en este punto entre dos contextos tan relacionados puede estar hablándonos de una concepción distinta de los perros, quizá vinculada a esas nociones de estatus.

\section{CONCLUSIONES}

Considero un esfuerzo yermo el tratar de defender la representatividad de una muestra como la que manejamos. No solo la diversidad contextual y cronológica, sino el grado de profundidad del análisis que viene condicionado por el estado de la muestra, son serios limitantes para ello. Sin embargo, los resultados obtenidos a raíz de la estrategia metodológica plasmada vaticinan una heterogeneidad en lo que respecta a los depósitos fúnebre de humano y perro que hemos estudiados. Estos contextos primarios y la diversidad de datos que desprenden contrastan con las interpretaciones monologuistas generalizadas para la región del Occidente. El perro como elemento psicopompo se adueña de la argumentación, en un fenómeno que a la luz de nuestro análisis trasciende los límites de la tumba.

Como hemos visto, la mayoría de los casos podrían entrar bajo este marco interpretativo en un inicio, lo cual no es cuestión azarosa. Son escasos los ejemplos zooarqueológicos que profundicen en contextos primarios más allá de lo fúnebre en el Occidente, así como es frecuente la descontextualización de los huesos de animales. Esto cercena la perspectiva desde la que analizar el fenómeno, lo que hace que se enfatice aquello que podría ser específico. En cualquier caso, resulta necesario ahondar en este diverso campo para entender con mejores perspectivas el desarrollo cultural de los grupos humanos del Occidente de Mesoamérica. La presente aportación da buena cuenta del potencial que la investigación zooarqueológica tiene en la región. Un nicho de estudio en el que hemos querido poner ese acento, y en donde aún el perro tiene mucho que ladrar.

\section{AGRADECIMIENTOS}

Este trabajo no hubiera sido posible sin la acogida del Colegio de Michoacán y la ayuda que el CONACYT me ha otorgado durante dos años de maestría. Personas como el Dr. Rodrigo Esparza López, la Dra. Maldonado, el Dr. Valadez, el Dr. Bernardo y el Dr. Götz fueron claves en el desarrollo de la tesis. Mención especial merece la Red de Ciencias Aplicadas a la Investigación y Conservación del Patrimonio Cultural y la Dra. Fabiola Vega, facilitadores de las dataciones numéricas y la lectura por XRF. Mi más profundo agradecimiento a la Mtra. Eugenia, el Antro. Fic. Humberto Quiroz, el Mtro. Ramiro Aguayo, La Mtra. Antonieta Moguel, la Mtra. Margarita Carballal y a cada una de las personas a las que me acerqué y me tendieron la mano en todo este proceso.

\section{REFERENCIAS}

Aguayo Haro, R. \& Quiroz Castañón, H. 2014: La Mina: Un pequeño asentamiento a orillas del lago de Cuitzeo. INAH Michoacán, Morelia, México.

Baker, J.R. \& Brothwell, D. 1980: Animal diseases in archaeology. Academic Press, New York.

BAR-Oz, G. \& Munro, N.D. 2004: Beyond Cautionary Tales: A Multivariate Taphonomic approach for resolving equifinalitu in zooarchaeological studies. Journal of Taphonomy 2: 201-222.

B aus Czitrom, C. 1988: Los perros de la antigua provincia de colima: estudio y corpus de sus representaciones en arcilla en las colecciones del Museo Nacional de Antropología. Instituto Nacional de Antropología e Historia, México D.F.

BeEkman, C.S. 2010: Recent research in western mexican archaeology. Journal of Archaeological Research 18(1): 41-109.

Betancourt López, J.A. 2013: Estado nutricional y de salud de individuos de la zona arqueológica Los Guachimontones en Teuchitlán, Jalisco a Través del Análisis de Restos Óseos Prehispánicos. Tesis de licenciatura. 
Blanco Padilla, A.; Rodríguez Galicia, B. \& Valadez AzÚA, R. 2009: Estudio de los cánidos arqueológicos del México prehispánico. INAH y IIA-UNAM, México D. F.

Brito Mayor, A. 2017: A dos y a cuatro patas: el Occidente de Mesoamérica y la relación entre el perro, el humano y viceversa... Una aproximación a través de estudios de caso.Tesis de maestría. CEQ-Colegio de Michoacán.

Brito Mayor, A.; Quiroz Castañón, H. \& Aguayo Haro, R. 2017: Más allá de la murte y la vida: zooarqueología de cánidos en el complejo funerario del sitio de La Mina (Michoacán). XIX Juan Comas, Morelia, Michoacán.

Brittain, M. \& Overton, N. 2013: The significance of others: a prehistory of rhythm and iterspecies participation. Society \& Animals 21: 134-149.

Cabrero García, M.T. 1995: La muerte en el occidente del México prehispánico. IIA-UNAM, México.

Cabrero García, M.T. \& Valadez Azúa, R. 2009: El perro en el sitio arqueológico de Pochotitan, Jalisco. AMMVEPE 20(4): 85-94.

Carot, P. 2001: Le site de Loma Alta, Lac de Zacapú, Michoacán, Mexique. Paris monographs in American archaeology Vol. 9. Archaeopress, Oxford.

Cuevas Sagardi, M.; Olvera, J.J.H. \& Ruiz, R.P. 2013: Consideraciones en torno a la dinámica cultural del sitio costero Valle de las Garzas, Manzanillo, estado de Colima, durante el 450 al 650 d.C. Trace. Travaux et recherches dans les Amériques du Centre 64: 25-43.

Cupul Magaña, F.G.; Mountjoy, J.B. \& Rhodes, J.A. 2014: Dientes de cánido (Canidae) asociados a un entierro del periodo Formativo medio en el valle de Mascota, Jalisco. Arqueología 48: 69-76.

DrIESCH, A. von den 1976: A guide to the measurement of animal bones from archaeological sites. Peabody Museum Bulletins, Harvard University.

FloRes, D. 1992: Ofrendas funerarias de chupicuaro, guanajuato. Instituto Nacional de Antropología e Historia, INAH, México.

GÁNDARA, M. 2011: El análisis teórico en ciencias sociales, aplicación a una teoría del origen del estado en mesoamérica. El Colegio de Michoacán, Zamora, Michoacán, México.

Goguitchaichvili,A.; Morales, J.; Haro, R.A.; Castañon, H.Q. \& CAMACHO, J.R. 2016: First evidence of complex dental practice about $1300 \mathrm{BP}$ in Mesoamerica revealed by absolute geomagnetic intensity. Studia Geophysica et Geodaetica 61: 310-317.

Göтz, C.M. (ed.) 2014: La arqueologia de los animales de mesoamerica. Lockwood Press, Atlanta GA.
Hernández Olvera, J.J.; Meraz Moreno, A. \& Moguel Cos, M.A. 2012: Prácticas funerarias durante las fases Colima y Armería en un sitio costero de Manzanillo, estado de Colima. Memorias del VII Foro Colima y su Región Arqueología, antropología e historia: 20-38.

Hillson, S. 2005: Teeth. Cambridge University Press, New York.

HodDer, I. 1991: Interpretative Archaeology and its role. American Antiquity 56: 7-18.

JARDÓN NAVA, E. 2004: Determinación taxonómica de los restos arqueozoológicos recuperados en el Proyecto Arqueológico Guachimontones. Informe del Proyecto Arqueológico Teuchitlán.

MarciniaK, A. 1999: Faunal materials and interpetive archaeology: epistemology reconsidered. Journal of Archaeological Method and Theory 6: 293-320.

Monteros Guijón, A. 2011: Informe de excavación pozo 22, extensiva 1, Patio de Maiobras Tepalcates II. Informe de la Dirección General de Salvamento Arqueológico.

Montiel Mendoza, M.; Mora Sánchez, C.; PérezRoldán, G.; Serrano Sánchez, C. \& Valadez Azúa, R. 2008: Análisis radiográfico de mutilación dentaria en Tantoc. Catálogo de la colección de dientes mutilados prehispánicos IV parte. Anales de Antropología 42: 9-30.

Mountuoy, J.; Cupul Magaña, F.G. \& Rhodes, J.A. 2014: El Perro en Contextos Funerarios, Valle de Mascota, Jalisco. Arqueología Mexicana 125: 54-57.

Muñoz Camargo, D. 1892 [1576-1591]: Historia de Tlaxcala. Oficina Tipográfica de la Secretaria de Fomento, México. Documento electrónico, http://www. cervantesvirtual.com/buscador/?q=historia+de+tlaxcala\#posicion, última consulta Agosto 8, 2018.

Nicolescu, B. 2002: Manifesto of transdisciplinarity. SUNY series. State University of New York Press, Albany.

Overton, N.J. \& Hamilakis, Y. 2013: A manifesto for a social zooarchaeology. Swans and other beings in the mesolithic. Archaeological Dialogues 20: 111-136.

Pijoan Aguadé, C.M.; Valenzuela Jiménez, G. \& LeboREIRO, I. 2010: Experimentos de Exposición Térmica de Huesos. En: Pijoan Aguadé, C.M.; Lizarraga Cruchaga, X. \& Valenzuela Jiménez, G. (eds.): Perspectiva tafonómica. Colección Científica. Instituto Nacional de Antropología e Historia, México, D.F.

Porter, M.N. 1956: Excavations at Chupicuaro, Guanajuato, Mexico. Transactions of the American Philosophical Society 46(5): 515.

Ramos Novelo, C. 2009: El papel del perro (Canis lupus familiaris) en la sociedad maya prehispánica de las 
tierras bajas del norte. Tesis de Licenciatura. Universidad Autónoma de Yucatán.

RAMSEY, C.B. 2009: Bayesian Analysis of Radiocarbon Dates. Radiocarbon 51(1): 337-360.

ReIMER, P.J.; BARD,E.;BAYLISS, A.;BECK, J.W.;BLACKWELl, P.G.; Bronk Ramsey, C.; Grootes, P.M.; Guilderson, T.P.; Haflidason, H.; Hajdas, I.; Hattž, C.; Heaton, T.J.; Hoffmann, D.L.; Hogg, A.G.; Hughen, K.A.; Kaiser, K.F.; Kromer, B.; Manning, S.W.; Niu, M.; Reimer, R.W.; Richards, D.A.; Scott, E.M.; Southon, J.R.; StafF, R.A.; Turney, C.S.M. \& Van Der Plicht, J. 2013: IntCal13 and Marine13 radiocarbon age calibration curves 0-50,000 years cal BP. Radiocarbon 55(4).

RodríGuez Galicia, B. 2000: Estudio morfológico y morfométrico, craneal y dental de perros y lobos hallados en Teotihucan y su aplicación en la arqueozoología. Tesis de Licenciatura en Biología. Facultad de Ciencias, UNAM. México.

Rodríguez Galicia, B.; Valadez Azúa, R.; Pereira, G.; Viniegra Rodríguez, F.; Olmos Rodríguez, K. \& Blanco Padilla, A. 2001: Restos arqueozoológicos de perros (Canis familiaris) encontrados en el Sitio de Guadalupe, Estado de Michoacán. AMMVEPE 12(6): 199-209.

Rodríguez Galicia, B.; Valadez Azúa, R.; Cabrero García, M.T. \& García Giménez, J.C. 2012: Arqueofauna del sitio El Piñón, Cultura Bolaños, Jalisco, México. Revista del Museo de Antropología 5: 203212.

Ruscillo, D. 2003: Alternative methods for identifying sex from archaeological bone. British School at Athens Studies 9: 37-44.

Russell, N. 2012: Social Zooarchaeology. Cambridge University Press, Cambridge.

Sahagún, B. de 1577: Historia general de las cosas de nueva España. World Digital Library. Documento electrónico, https://www.wdl.org/en/item/10096/\#q=Sahag\%C3\%BAn\&qla=en Último acceso Agosto 8, 2018.

SAINZ de los Terreros, J.Y. 2013: Tafonomía aplicada a zooarqueología. UNED Ediciones, Madrid.
TAYLOR, R.E. 1970: The Shaft Tombs of Western Mexico. Problems in the Interpretation of Religious Function in Nonhistoric Archaeological Contexts. American Antiquity 35(02): 160-169.

Valadez Azúa, R. \& Blanco, A. 2005: Perros, Maíz, el México Prehispánico. AMMVEPE 16(2): 63-70.

Valadez Azúa, R.; Paredes Gudiño, B. \& RodrígueZ Galicia, B. 1999: Entierros de perros descubiertos en la antigua ciudad de Tula. Latin American Antiquity 10(2): 180-200.

Valadez Azúa, R.; Gamboa, L.; Vélez, N.; RodríGuez Galicia, B.; Gómez, M.; García, R. \& Pére, G. 2004: Perros y Prácticas Rituales en una Antigua Aldea de la Cuenca de México. AMMVEPE 15(5): 158-171.

Valadez Azúa, R.; Tejeda Vega, S.; Zarazúa Ortega, G.; Carapia Morales, L. \& Casas Castillo, M. 2005: El estudio de elementos traza en restos arqueozoológicos y su empleo en la reconstrucción de paleodietas. Estudios de Antropología Biológica 12(2): 945-969.

Valadez Azúa, R.; Rodríguez Galicia, B. \& Blanco Padilla, A. 2010: Flujos migratorios e influencias culturales entre el Centro, el Occidente y el Norte de Mesoamérica, vistos a través de la fauna doméstica. In: Dinámicas culturales entre el Occidente, el Centro-Norte y la cuenca de México, del Preclásico al Epiclásico: 231-245. Centro de estudios mexicanos y centroamericanos. México.

Valadez Azúa, R.; Blanco Padilla, A.; Rodríguez Galicia, B.; Viniegra Rodríguez, F. \& Olmos Jiménez, K. 2013: La investigación etnozoológica y el estudio del cánido mesoamericano. AMMVEPE 14(6): 186194.

Weigand, P.C. \& Esparza López, R. 2008: Informe de excavaciones 2003-2006 en el Complejo Arqueológico Guachimontones "La Tradición Teuchitlán del Occidente de México”. Informe del Proyecto Arqueológico Teuchitlán.

Winning, H. Von; Weigand, P.C. \& Williams, E. 1996: El arte prehispánico del occidente de México. El Colegio de Michoacán, Secretaria de Cultura de Jalisco, Zamora, Michoacán, México. 